Check for updates

London, UK

Cite this as: BMJ 2020;370:m2804 http://dx.doi.org/10.1136/bmj.m2804 Published: 10 July 2020

\section{Covid-19: Symptoms are common after acute phase of disease, Italian study shows}

\author{
Jacqui Wise
}

Almost nine out of 10 patients discharged from a Rome hospital after recovery from covid-19 were still experiencing at least one symptom two months later, a study shows.

Fatigue and shortness of breath were the most common symptoms reported in the study of 143 patients. ${ }^{1}$ More than half of patients were still experiencing three or more symptoms.

The research, published as a letter in JAMA, is further evidence of a "long tail" of covid-19 related illness. On 5 July health and social care secretary Matt Hancock announced the launch of a study into the long term health effects of covid-19 on hospitalised patients in the UK. The post-hospitalisation covid-19 study aims to recruit 10 ooo patients who have been hospitalised with covid-19 and will track them over a year. ${ }^{2}$

In the waning phase of the pandemic in Italy, beginning on 21 April, the Fondazione Policlinico Universitario Agostino Gemelli hospital established a post-acute outpatient service for patients discharged from the hospital after recovering from covid-19. The mean age of the patients was 56.5 years and $63 \%$ were men. They had been in hospital for an average of 13.5 days and $72 \%$ had evidence of interstitial pneumonia. Some $15 \%$ of patients had received non-invasive ventilation and $5 \%$ had received invasive ventilation.

The patients were only included in the study if they had a negative transcriptase polymerase chain reaction test for SARS-CoV-2, indicating they were not in the acute phase of the illness.

When patients were assessed a mean of 60 days after onset of the first covid-19 symptoms, only $18(12.6 \%)$ were completely free of any covid-19 related symptom, while $32 \%$ had one or two symptoms, and $55 \%$ had three or more. None of the patients had fever or any signs or symptoms of acute illness. Worsened quality of life was reported by $44 \%$ of patients. A high proportion of patients still reported fatigue $(53 \%)$, dyspnea $(43 \%)$, joint pain $(27 \%)$, and chest pain (22\%).

The study has limitations as it is based on a single centre with a relatively small number of patients and without a control group of patients discharged for other reasons. There is also a lack of information on symptom history before acute covid-19 illness and no information on symptom severity. Furthermore, the study authors point out that patients with community acquired pneumonia can also have persistent symptoms.

1 Carfi A, Bernabei R, Landi FGemelli Against COVID-19 Post-Acute Care Study Group. for the Gemelli Against Ccovid-19 Post-Acute Care Study Group. Persistent symptoms in patients after acute covid-19. JAMA 2020;9. doi: 10.1001/jama.2020.12603. pmid: 32644129

2 Post-hospitalisation covid-19 study. www.phosp.org.

This article is made freely available for use in accordance with BMI's website terms and conditions for the duration of the covid-19 pandemic or until otherwise determined by BMJ. You may use, download and print the article for any lawful, non-commercial purpose (including text and data mining) provided that all copyright notices and trade marks are retained. 